\title{
O portfólio como instrumento de autoavaliação crítico reflexiva na perspectiva dos alunos de um curso de medicina
}

\author{
The portfolio as a tool for critical self-assessment on \\ medical school student's reflexive perspective
}

\author{
Clóvis José Vieira da Silva', Aline Oliveira Ferraz¹, Nara Macedo Botelho² \\ 'Centro Universitário do Estado do Pará, Belém (PA), Brasil. \\ Universidade do Estado do Pará, Belém (PA), Brasil.
}

\begin{abstract}
RESUMO
Objetivo: Avaliar o portfólio utilizado no módulo de Interação em Saúde na Comunidade como instrumento de autoavaliação crítico reflexiva na perspectiva dos alunos do curso de medicina do Centro Universitário do Estado do Pará. Métodos: Estudo transversal, observacional e descritivo, com abordagem qualitativa. Foram entrevistados 24 participantes, distribuídos em dois grupos de 12 alunos do 9 e do 10 semestre do curso. Resultados: As opiniões dos alunos, reveladas nas entrevistas, demonstraram que o portfólio foi utilizado diariamente do primeiro ao oitavo semestre do curso e que sofreu uma série de alterações em seu modelo. Os alunos referiram que no início o instrumento era desnecessário, confuso e que nem os professores tinham conhecimento e opinião convergentes sobre ele. Com as alterações e a inclusão do Feedback em seu modelo, transformou-se em primordial, importante e necessário. Conclusão: O portfólio foi avaliado e referendado como instrumento de autoavaliação crítico reflexiva. O estudo permitiu a obtenção de informações que podem subsidiar o processo de avaliação formativa através do portfólio crítico reflexivo e adequação do ensino médico no referido curso de medicina às necessidades da população brasileira assistida pelo SUS.
\end{abstract}

PALAVRAS-CHAVES: Graduação em medicina. Avaliação. Portfólio.

Recebido: Maio 31, 2016 Aceito: Set. 11, 2016

COMO CITAR ESTE ARTIGO

Silva CJV, Ferraz AO, Botelho NM. O portfólio como instrumento de autoavaliação crítico reflexiva na perspectiva dos alunos de um curso de medicina. Interdisciplinary Journal of Health Education.

\section{CORRESPONDÊNCIA}

Nara Macedo Botelho

Travessa Perebebuí, 2623, Marco, CEP 66087-670, Belém (PA), Brasil narambotelho@gmail.com

FONTE DE FINANCIAMENTO

Nenhuma.

CONFLITO DE INTERESSE

Os autores declararam não

haver conflitos de interesse.

O estudo foi realizado no Centro

Universitário do Estado do

Pará, Belém (PA), Brasil.

Este trabalho é resultado de dissertação de mestrado de

Health Education (IJHE).

\section{ABSTRACT}

Objective: to evaluate the interaction module portfolio in Community Health as a tool for critical self-assessment on medical school student's reflexive perspective at University Centre of Para State. Method: this is a cross-sectional, observational and descriptive study, with a qualitative approach carried out according to ethical principles. 24 students participated in the research being 12 in step 9 and 12 in step 10 distributed into two groups. Results: the opinions of students, revealed in the interviews, demonstrated that the portfolio is daily used from step 1 up to 8 and it experienced a series of changes to its model. Students found earlier that the instrument was unnecessary, confusing and even teachers had a nonhomogeneous knowledge and opinion about it. With the changes, and the inclusion of Feedback in its model it has become paramount, important and necessary. Conclusion: The portfolio was valued and endorsed as critical reflective self-assessment instrument. The study allowed it to obtain information that will subsidize the formative assessment process through critical reflective portfolio and adequacy of medical education at CESUPA's medical school to the Brazilian population's necessities assisted by SUS.

KEYWORDS: Graduation in medicine. Evaluation. Portfolio. 


\section{Introdução}

Com as Diretrizes Curriculares Nacionais (DCN) para os Cursos da Área da Saúde do Conselho Nacional de Educação (CNE), homologadas pelo Ministério da Educação (MEC), o perfil do egresso do curso de graduação em medicina passou a ter uma definição mais específica de acordo com as necessidades apontadas pelo Sistema Único de Saúde, priorizando-se o médico com formação generalista, humanista, crítica e reflexiva e que atue na promoção, prevenção, recuperação e reabilitação à saúde, considerando a integralidade da assistência ${ }^{1}$.

A inserção precoce dos alunos na rede básica de saúde busca propiciar a compreensão das circunstâncias ambientais, socioculturais e econômicas das quais emergem as condições de saúde e seus agravos ${ }^{2}$. Ao colocar o estudante em contato com diferentes realidades sociais, econômicas e culturais, um programa de aprendizagem em atenção básica favorece o exercício da ética e a estruturação da ideia de que o indivíduo deve ser compreendido em sua totalidade, com peculiaridades biopsicossociais próprias ${ }^{3}$.

Assim, o perfil do egresso exigido pelas DCN da graduação em medicina faz com que as escolas médicas passem a se preocupar em como irão formar este profissional. No entanto, a metodologia ativa de ensino-aprendizagem, que é centrada no aluno, tendo o professor como facilitador da construção do conhecimento, ainda não foi implantada em todas as escolas médicas brasileiras. É preciso entender que o estudante deve conhecer as diversas realidades existentes na vida da população, no sentido de dar a oportunidade para que vivenciem situações reais, mesmo que, em alguns momentos, experimentem algumas frustrações ${ }^{4}$.

Educar o profissional para ser reflexivo é um processo em que discente e docente interagem de maneira integrada. É imprescindível que o aluno aprenda a fazer fazendo, aplicando o conhecimento prévio e refletindo na ação, bem como, depois dela. A orientação para a prática reflexiva pressupõe que a formação de bons principiantes tem a ver, acima de tudo, com a formação de pessoas capazes de evoluir, de aprender de acordo com a experiência, refletindo sobre o que gostariam de fazer, sobre o que realmente fizeram e sobre os seus resultados ${ }^{5}$.

Dentro desta visão, o portfólio pode ser considerado um procedimento capaz de fazer o aluno refletir e criticar suas próprias ações. Constitui-se da compilação de trabalhos realizados por ele durante um curso ou uma disciplina. Inclui, entre outros, registros de visitas, resumo ou fichamento de textos, projetos, relatórios de pesquisa e, principalmente, ensaios reflexivos que permitem aos alunos a discussão de como a experiência mudou sua vida, podendo acompanhar e avaliar o seu aprendizado, registrando a organização dos saberes e demonstrando todo um processo de construção de conhecimento ${ }^{6}$.

Neste tipo de procedimento é preciso entender a visão do professor, que tem que assimilar a importância da avaliação como um processo dinâmico em que o retorno para o aluno deve ser sempre contemplado o mais breve possível. Além de selecionar e ordenar evidências de aprendizagem do aluno, o portfólio possibilita também identificar questões relacionadas ao modo de os estudantes e educadores refletirem sobre os reais objetivos de sua aprendizagem, quais foram cumpridos e os que ainda precisam ser alcançados ${ }^{7}$.

Ao permitir que a decisão tenha origem na avaliação do próprio aluno, o professor o estimula a se transformar em um profissional crítico e reflexivo, construindo o seu próprio saber. A "reflexão na ação" irá induzi-lo a procurar novas informações para solucionar problemas e construir seu conhecimento. É preciso unir saber e experiência, e a escola tem a missão de fazer, no registro do discurso, a referência a um futuro abstrato em que o aluno compreenderá que tudo que está aprendendo agora será indispensável para sua vida pessoal e profissional ${ }^{8}$.

Atendendo às DCN do curso de graduação de Medicina, o Centro Universitário do Estado do Pará (CESUPA) acrescentou em sua matriz curricular o Módulo de 
Interação em Saúde na Comunidade (MISC) que é uma atividade de integração universidade-comunidade desenvolvida na Atenção Primária à Saúde, fazendo parte da Estratégia Saúde da Família, com alunos do primeiro ao oitavo semestre do curso. O MISC faz parte de uma proposta educacional baseada na vivência social, com trabalho em equipe multiprofissional e interdisciplinar e utiliza o portfólio como instrumento de autoavaliação crítico reflexivo, que permite ao aluno refletir sobre a construção dos seus próprios conhecimentos'.

Dentre seus principais objetivos, o MISC visa proporcionar aos alunos experiências que viabilizem o desenvolvimento de habilidades interpessoais para trabalhar em grupo e em equipe interdisciplinar e multiprofissional, além de promover o conhecimento das políticas públicas de saúde do Ministério da Saúde, especificamente na área da atenção primária.

O cenário do MISC são as Unidades de Saúde da Família (USF) dos municípios de Belém e de Ananindeua, região metropolitana da capital do Estado do Pará e suas áreas adstritas que incluem grupos sociais, escolas, locais de trabalho, instituições sociais e famílias. As atividades são desenvolvidas em um período de quatro horas semanais, ao longo do semestre, e os alunos são distribuídos em subturmas formadas por seis alunos e um professor.

Em dia de atividade do MISC o aluno registra no portfólio manuscrito as atividades desenvolvidas com suas conclusões e autoavaliação de forma textual, em um modelo pré-estabelecido pela instituição de ensino. O portfólio é, então, entregue ao professor que o utilizará para coordenar a narrativa diária individual de cada aluno, ofeedback do professor e o cálculo da nota ao final do dia de atividade.

Entretanto, o modelo de portfólio já sofreu diversas modificações ao longo do curso de medicina, começando por um modelo aberto, em que o aluno discorria livremente sobre determinada atividade ou assunto, passando a perguntas fechadas, mas sem nunca terem sido avaliados como instrumento de autoavaliação pelos alunos.

Em função do exposto, essa pesquisa objetivou avaliar o portfólio como instrumento de autoavaliação crítico reflexiva na perspectiva dos alunos do curso de medicina do CESUPA.

\section{Método}

Trata-se de um estudo transversal, observacional, descritivo, com abordagem qualitativa. A pesquisa foi iniciada após a aprovação do projeto de pesquisa pelo Comitê de Ética em Pesquisa (CEP) do CESUPA por meio de cadastramento na Plataforma Brasil, CAAE N 11846312.60000 .5169 . O local das entrevistas foi a sala da Coordenação do MISC, nas dependências da biblioteca do Curso de Medicina do CESUPA em Belém/Pará.

O critério de inclusão para o estudo consistiu em: ser aluno regularmente matriculado na $9^{a}$ ou $10^{a}$ etapa ( $5^{\circ}$ ano) do Curso de Medicina do CESUPA, por já ter finalizado suas atividades do MISC. Durante o primeiro semestre de 2013 foram realizadas 24 entrevistas semiestruturadas, com 12 alunos da $9^{\text {a }}$ etapa e 12 da $10^{\text {a }}$ etapa, após aceitação voluntária e assinatura do Termo de Consentimento Livre e Esclarecido pelos participantes.

As entrevistas foram realizadas individualmente e adotou-se o seguinte roteiro:

1. Quando foi que você começou a usar o portfólio crítico reflexivo do MISC? O que achou de imediato? Como foi o seu uso no começo?

2. Você utilizou o portfólio diariamente? Como usou o portfólio? O que registrou? Quando fez o registro?

3. Como o professor usou o portfólio no MISC? O que ele fez? Como fez?

4. Como você avalia a utilização do portfólio? Para que serviu? Quais as vantagens? Quais as fragilidades? Quais as contribuições? 
5. Como você avalia o uso do portfólio pelo professor?

6. Você mudaria alguma coisa no modelo de portfólio? O que? Por quê? Dê sugestões.

7. Ele poderia ser usado em outras disciplinas? Por quê? Quais?

A coleta de dados foi realizada com gravação das entrevistas e posterior transcrição, sendo concluída após atingir a saturação teórica. O fechamento amostral por saturação teórica é operacionalmente definido como a suspensão de inclusão de novos participantes quando os dados obtidos passam a apresentar, na avaliação do pesquisador, redundância ou repetição, não sendo considerado relevante persistir na coleta de dados ${ }^{10,11}$.

A análise dos resultados foi realizada segundo as teorias da análise de conteúdo ${ }^{12}$ e dividida em três etapas: pré-análise (organização do material a ser analisado para que possa transformá-lo em operacional), exploração do material (definição de categorias e unidades de registro) e tratamento dos resultados (interpretação das informações a partir da análise reflexiva e crítica). A análise de conteúdo foi do tipo categoria temática ${ }^{13}$.

\section{Resultados}

Observou-se que a participação foi ligeiramente maior das alunas $(54,16 \%) \mathrm{em}$ relação aos alunos (45,84\%). Em relação à faixa etária, os dois grupos mantêm uma média compatível à etapa letiva em que se encontram (9a etapa: 23,5 anos; $10^{a}$ etapa: 24,6 anos). As idades superiores ( 29 e 36 anos) correspondem a alunos que já tinham uma primeira graduação e decidiram fazer o curso de medicina posteriormente.

Em relação à pergunta "Quando foi que você começou a utilizar o portfólio crítico reflexivo do MISC? O que achou de imediato? Como foi seu uso no começo?", observa-se que houve uma coincidência quanto ao início da utilização do portfólio desde o primeiro semestre do curso de medicina. Acostumados à metodologia tradicional, os alunos reagiram bastante ao novo processo - "não estávamos acostumados" - considerando-o "extenso e confuso", "maçante, cansativo e repetitivo", "servia somente para a avaliação", "sem feedback", dependente da atuação do professor e que "nem tinham certeza de que era lido" e por isto achavam que era "perda de tempo".

Pelo fato de ter tido diversas modificações, demonstra que nem os professores eram portadores das informações necessárias para a sua utilização. As mudanças surtiram os efeitos desejados, especificamente quanto ao feedback a ser dado diariamente ao aluno, caracterizando o método formativo da avaliação. Confirmando estas considerações a resposta de uma aluna exemplifica bem esta condição:

O portfólio foi sofrendo modificações ao longo desses anos. Dependia muito do tipo de metodologia que o professor empregava. Alguns professores preferiam solicitar que a gente escrevesse de um assunto que tinha visto no dia. Exemplo: se tínhamos visto casos interessantes de hipertensão, pesquisávamos sobre a doença. Outros professores preferiam que a gente relatasse o que tinha acontecido naquele dia. Eu gostava muito do modelo de portfólio baseado nos temas científicos que a gente via no MISC. Embora eu ache que era um modelo que demandava mais tempo, mais trabalho, já o modelo atual é bem mais prático e acho que reflete bem para o CESUPA o que estávamos realizando nas nossas atividades, mas pra mim como pessoa, eu prefiro o dos temas. No começo [primeiro semestre] eu me sentia meio perdida, não sabia para que servia, mas à medida que o professor explicava a gente entendia para que serve o portfólio e hoje eu já entendo que o portfólio serve para verificar quais são as atividades que estão sendo realizadas no MISC.

Em relação à frequência com que eram feitos, em resposta à pergunta "Você utilizou o portfólio diariamente? Como usou o portfólio? O que registrou? Quando fez o registro?", todos confirmam que "eram feitos diariamente", mas "às vezes o professor esquecia" e "permitia que entregassem na semana seguinte", servindo somente para o "registro das atividades" e para ver as "falhas". A opinião de um aluno exemplifica bem esta situação: 
Toda vez que tinha o MISC nós utilizamos. No início, eu não pensava muito, escrevia bem curtinho o que fazia no nosso dia-a-dia [...]. Eu acho que não era muito fidedigno, porque por ser uma obrigação eu acabava escrevendo qualquer coisa. A gente fazia os atendimentos e se tinha algum caso interessante, eu descrevia. Uma vez, chegou uma paciente com amenorreia e ela já tinha três filhos, como era um caso interessante eu descrevi. Aí relatava o que a gente fez, depois a minha participação durante a consulta e no final sempre tinha um debate sobre os atendimentos, claro com o olhar voltado na saúde da família, era isso. Ao final do dia, depois de todos os debates [...] era entregue pra gente uma folha e a gente tinha que devolver logo em seguida, a gente escrevia o que precisasse, escrevia e devolvia.

Em relação à conduta dos professores sob o ponto de vista dos alunos, quanto à resposta da pergunta "Como o professor usou o portfólio no MISC? O que ele fez? Como fez?", observa-se que os alunos não tinham muita certeza se eles recebiam uma boa orientação sobre o método porque não havia um comportamento homogêneo, pois "ele somente lia, corrigia e dava a nota", "não tinha feedback" e "alguns nem liam". Quando os professores discutiam com os alunos, estes consideraram que "aprendiam com as orientações", "aprenderam a refletir" quando passou a ter "contrapartida". Na verdade, "ninguém gostava do primeiro modelo", mas "com as mudanças passou a ser mais agradável". Uma aluna observou que:

Inicialmente eu achava que o que eu colocava no portfólio pouco era lido e às vezes eu me esforçava para tentar alcançar uma nota máxima e achava que a avaliação não era justa. E também não havia o feedback para chegar e "Fulana, olha! Faltou isto aqui, tá precisando estudar mais esta parte". Posteriormente com a mudança da estrutura do portfólio, ficou muito mais agradável e eu pude ter o retorno do professor de exaltar os pontos positivos do meu portfólio e criticar de maneira construtiva para que eu pudesse melhorar no próximo portfólio.

Em relação à questão "Como você avalia a utilização do portfólio? Para que serviu? Quais as vantagens? Quais as fragilidades? Quais as contribuições?", observou-se que nos dois grupos as opiniões são idênticas quando afirmam que houve diversos modelos de portfólio, que no início era monótono, que as mudanças foram positivas e destacam como a mais importante a introdução do feedback como uma oportunidade de aprender a refletir e aprender com as críticas dos professores, como demonstra a opinião de uma aluna:

No primeiro ou no geral? Bom! No geral, eu avalio que ele hoje tem uma utilidade. O último modelo de portfólio, eu vejo ele com uma utilidade boa pelo fato de ter o feedback. Eu, pelo menos, o feedback quando me criticava, eu sempre procurava melhorar naquilo onde eu recebia uma crítica. Eu ficava preocupada, "Ele me chamou atenção a respeito disso. Tenho que fazer desse jeito". Sabe, isto me fez melhorar bastante. E assim, como eu falei, a minha melhora mesmo seria a minha reflexão.

Observou-se que a aluna, nesta entrevista, já fala "ele me fez melhorar muito" e a "minha melhora seria mesmo a minha reflexão".

Quando perguntados sobre "Como você avalia o uso do portfólio pelo professor?", os alunos foram taxativos quanto à valorização positiva do feedback dado pelo professor. Considerando o portfólio como uma ferramenta de avaliação, demonstram suas dúvidas quanto ao fato de se realmente eram lidos pelo professor no período inicial, porque os professores não discutiam os portfólios com eles e demonstraram o interesse de ficar com o portfólio para acompanharem a sua evolução. Não eram todos que tinham este comportamento, havia certa heterogeneidade de conduta por parte dos docentes. A resposta de um aluno salienta bem esta situação:

Tive professores que utilizaram muito mal, somente servia para dar nota. Assim como eu tive professores que faziam uma avaliação fantástica, eles davam um feedback muito bom. Como eu falei, eu via que eles estavam ali, que estavam preocupados comigo. Mostrava interesse, mostrava que era importante aquilo que a gente estava fazendo. Ele fazia com que a gente desse valor ao portfólio e que não fizesse só por nota, somente por fazer.

Quando perguntados "Você mudaria alguma coisa no modelo de portfólio? O quê? Por quê? Dê sugestões", afirmam que as modificações mais importantes já ocorreram, mas ainda sugeriram algumas alterações como fazer sempre no mesmo dia, tirar a nota 
numérica da autoavaliação, fazer sempre ofeedback, incluir espaço para sugestões dos alunos e promover um momento de discussão ampla e aberta sobre as atividades do dia e o retorno das pesquisas que eram utilizadas no início. A resposta de um aluno representa bem estas opiniões do grupo:

Sim! O que precisa mudar na aula, o que precisa acrescentar... sugestões [...]. O resto já foi atendido. O que você fez... o que você precisa estudar... o que você aprendeu... a sua avaliação. Já tem todas as perguntas. Ah! Espaço para sugestões e perguntas para os professores [pesquisador: "Você prefere fazer no mesmo dia ou fazer uma semana depois?"] No mesmo dia. Nem todo mundo é disciplinado.

Perguntados se "Ele poderia ser usado em outras disciplinas? Por quê? Quais?", os participantes disseram que já foi utilizado na disciplina de Habilidades Clínicas e que era muito bem feito e não sabiam porquê não tinha mais. Nos demais módulos, com exceção da Tutoria que já tem uma forma de autoavaliação e avaliação interpares, deveria ter principalmente ofeedback que poderia ser oral desde que a atividade fosse prática, como ambulatórios, demonstrando que em qualquer situação os professores devem estar preparados para direcionar de maneira adequada para não prejudicar o processo de aprendizado. É importante, neste caso, salientar a opinião do aluno que afirma:

Eu acho que é assim. Pra ser usado o portfólio principalmente neste modelo tem que ser uma disciplina prática. Então não entraria tutoria, habilidades clínicas porque é uma prática já prevista, diferente de uma prática real. Então, a única maneira que eu vejo de utilizar em outro momento seria no internato, mas só que fica muito complicado por conta dos horários e da quantidade de cobranças que já existe. [Pesquisador: "e nas habilidades práticas?"] Não sei. Não vejo muita utilidade. Pera aí! Os ambulatórios estão lá nas habilidades práticas? Ah! É. Não tinha pensado nisso. Tem que ser prática. É! Nos ambulatórios como atividade prática, real e não de ator. Aí sim.

\section{Discussão}

Quanto ao início da utilização do portfólio desde o primeiro semestre do curso de medicina ambos os grupos afirmam que "não estávamos acostumados", considerando-o "extenso e confuso", "maçante, cansativo e repetitivo", "servia somente para a avaliação", "sem feedback", dependente da atuação do professor e que "nem tinham certeza de que era lido" e por isto achavam que era "perda de tempo", sendo compatíveis com autores que afirmam que a mudança de paradigmas nem sempre é fácil e atraumática, não só para os educandos, mas também para os educadores ${ }^{4,14}$.

A educação universitária deve ser longitudinal, contínua, prática, acessível e atraente $^{15}$. Uma das maneiras de se conseguir isto é a inclusão do feedback como prática reflexiva da qual os alunos sentem falta e que não é uma prática diária nas universidades. Uma característica da avaliação formativa é a realização do feedback imediato, permitindo ao aluno a obtenção de dados importantes da atividade educativa ${ }^{16}$.

Além do mais, observa-se que a falta de experiência e motivação dos professores foram fatores desencadeantes do comportamento dos alunos pelo fato de não realizarem o feedback todos os dias. É necessário, para que o portfólio seja aplicado como procedimento avaliativo e se adeque às teorias e definições encontradas na literatura, que os professores sejam capacitados na sua utilização de maneira homogênea ${ }^{17}$.

Vale salientar que a reflexão, a avaliação e o uso do portfólio estão intimamente interligados e requerem uma participação proativa dos professores no sentido de coletarem informações, analisarem e, num processo reflexivo, fazerem comentários reflexivos e escritos diariamente após cada atividade desenvolvida pelos alunos e relatadas no portfólio ${ }^{18}$. 
Em relação ao uso irregular do portfólio, que nem sempre era realizado no dia da atividade do MISC, este procedimento vai de encontro ao conceito de o portfólio ser um procedimento avaliativo processual em que a participação do aluno é primordial. O instrumento é definido como uma coleção especial dos melhores trabalhos selecionados e organizados pelo próprio aluno. A ação do professor deve realizada junto com o aluno e não só para $\mathrm{si}^{6,16}$.

Este entendimento inclui três ideias básicas: a avaliação é um processo em desenvolvimento; os alunos são participantes ativos desse processo por aprender a identificar e revelar o que sabem e o que ainda não sabem; a reflexão pelo aluno sobre sua aprendizagem é parte importante do processo ${ }^{6}$.

A heterogeneidade de conduta por parte dos professores complementa a ideia de que há necessidade de capacitação dos docentes no sentido de o processo avaliativo e o uso adequado do portfólio devem ser semelhantes, mesmo com as situações práticas diferentes encontradas nas diversas unidades de saúde de atuação do MISC ${ }^{19}$.

Em relação aos diversos modelos já utilizados, os alunos afirmam que no início era monótono, que as mudanças foram positivas e destacam como a mais importante a introdução do feedback como uma oportunidade de aprender a refletir e aprender com as críticas dos professores. O processo evolutivo da avaliação do MISC e o uso do portfólio como instrumento de autoavaliação demonstram a preocupação da instituição em aprimorar gradualmente os seus processos de ensino-aprendizagem e de avaliação através de treinamento dos professores para ouvirem os alunos ao final de cada semestre. Alternar de um procedimento "monótono" para "mais agradável" é uma a demonstração deste pensamento.

A avaliação dos alunos quanto ao uso do portfólio pelo professor foi taxativa quanto à valorização do feedback dado pelo docente nas alterações incluídas. Analisando o portfólio como uma ferramenta de avaliação, demonstram suas dúvidas quanto ao fato de se realmente eram lidos pelo professor no período inicial porque os professores não discutiam com eles e demonstraram o interesse de ficar com o portfólio para acompanharem a sua evolução. Mais uma vez salientaram a heterogeneidade de conduta por parte dos docentes.

Quanto a sugestões dos alunos em relação às alterações necessárias, observa-se que eles consideram que as mais importantes já ocorreram, mas ainda sugeriram algumas outras como fazer sempre no mesmo dia, tirar a nota numérica do portfólio, fazer sempre o feedback, incluir espaço para sugestões dos alunos e promover um momento de discussão ampla e aberta sobre as atividades do dia e o retorno das pesquisas que eram utilizadas no início.

Em relação a ser utilizado em outras disciplinas, os alunos responderam que o portfólio já foi utilizado nas Habilidades Clínicas e que era muito bem feito e não sabem por que foi retirado. Nos demais módulos deveria ter principalmente o feedback que poderia ser oral desde que a atividade fosse prática, como os ambulatórios.

Neste estudo, observa-se que os alunos já apresentam um questionamento sobre a importância do feedback em seu aprendizado em todos os módulos ou disciplinas, principalmente nas atividades práticas em que há contato direto com os pacientes. Estas evocações favorecem a percepção da importância das narrativas como parte integrante da avaliação como procedimento de pesquisa e como alternativa de formação, permitindo desvendar elementos não expressos nos escritos do próprio sujeito por que nunca tinham sido estimulados a fazê-lo ${ }^{20}$.

Por fim, entre alguns princípios coerentes em uma ação avaliativa mediadora, está o fato de dar oportunidade aos alunos de expressar suas ideias e promover discussão entre eles a partir de situações desencadeadoras e estimulantes ${ }^{21}$. 


\section{Conclusão}

Quanto à utilização do portfólio no MISC como instrumento de autoavaliação crítico-reflexiva, conclui-se que a inexperiência dos professores com a metodologia ativa e com utilização do portfólio contribuiu para que houvesse uma orientação heterogênea para os alunos desde o primeiro ano do curso de medicina, criando uma certa rejeição ao processo avaliativo do MISC tornando a realização do portfólio enfadonho e pouco produtivo. À medida que alunos e professores foram adquirindo experiência com o método e as alterações foram realizadas, no sentido de tornar o portfólio mais reflexivo, houve uma melhora nas opiniões e aceitação do instrumento de avaliação.

Em relação às potencialidades, fragilidades, utilização e contribuições do portfólio para a formação crítico reflexiva, conclui-se que a falta de feedback nas atividades diárias por parte de alguns professores que se limitavam a dar uma nota sem que o aluno soubesse como fazer as correções, associada a alguns hiatos por desinteresse e "esquecimento" dos professores de realizarem adequadamente o processo avaliativo diário, foram fatores negativos na fase inicial das atividades do MISC. As mudanças do modelo do portfólio no sentido de tentar adequá-lo à metodologia ativa e à avaliação formativa são elogiáveis, no entanto observa-se a necessidade de aperfeiçoá-lo criando oportunidades de pesquisas e estudos e torná-lo mais crítico, reflexivo, agradável e produtivo.

Em relação às sugestões dos alunos para melhorar a utilização do portfólio na avaliação do MISC conclui-se que a atribuição de notas ao instrumento de autoavaliação ou a sua utilização exclusivamente para dar nota não é uma conduta adequada. $\mathrm{O}$ arquivamento dos portfólios na instituição em pastas individuais de cada aluno também tem que ser repensado porque coíbe o estudante de ter consigo aquilo que sempre lhe pertenceu.

Para validar um modelo de portfólio crítico reflexivo para avaliação formativa do MISC na perspectiva dos alunos, conclui-se que é necessário criar um portfólio mais completo, incluindo questionamentos mais reflexivos e menos descritivos, com itens de sugestões e críticas dos alunos e orientações quanto a pesquisas a serem realizadas para discussão futura.

Com bases nas conclusões, recomenda-se a realização de oficinas de capacitação para os professores atuais e para aqueles que venham a se incorporar ao MISC sobre metodologias ativas, principalmente a problematização e uso adequado do portfólio crítico reflexivo dentro das suas definições científicas encontradas na literatura no sentido de unificar a conduta dos docentes e evitar comparações negativas.

Sugere-se adotar uma aplicação sistemática do feedback, diariamente, no sentido de dar ao aluno a oportunidade de corrigir a seu tempo aquilo que for necessário para a sua formação, além de promover a prática diária da narrativa ao final de cada atividade no sentido de complementar o portfólio escrito.

A utilização de um portfólio crítico reflexivo permite o acompanhamento, por parte dos professores, se realmente os alunos cumpriram os acordos de estudar e realizar pesquisas necessárias ao seu crescimento, não se devendo atribuir nota ao portfólio, considerando-o como um procedimento de autoavaliação em que os conteúdos definem como as atividades foram desenvolvidas e se o aluno assimilou as informações previstas para aquele dia.

Deve-se ainda entregar o portfólio ao aluno no mesmo dia no sentido de permitir que ele se aposse daquilo que realmente lhe pertence e o utilize como instrumento de autoavaliação crítico reflexiva.

Espera-se que o trabalho tenha contribuído para avaliação do Módulo de Interação em Saúde na Comunidade do curso de Medicina do Centro Universitário do Estado do Pará, principalmente no item avaliação formativa e utilização adequada do portfólio como instrumento de autoavaliação crítica e reflexiva por parte dos discentes, uma vez que se priorizou a opinião dos protagonistas do ensino em que a metodologia ativa é aplicada. 


\section{ijhe}

\section{Referências}

1. Brasil. Ministério de Educação e Cultura. Conselho Nacional de Educação. Câmara de Educação Superior. Resolução CNE/ $\mathrm{CES} \mathrm{n}^{\circ}$ 4, de 7 de novembro de 2001. Institui Diretrizes Curriculares Nacionais do Curso de Graduação em Medicina. Diário Oficial da União, Brasília, DF, 9 nov. 2001. Seção 1, 38p.

2. Andrade MR. O perfil médico a ser formado no novo projeto de graduação em Medicina. Escolas Médicas do Brasil [Internet]. 2010 [citado em 2012 Ago 29]. Disponível em: www.escolasmedicas.com.br/art_det.php?cod=181.

3. Trindade DG, Cornetta MCM, organizadores. Manual do Programa de Aprendizagem em Atenção Básica. Natal (RN): Edunp; 2011. 29 p.

4. Silva CJV, Botelho NM. A formação médica e a assistência humanizada: o papel da educação e do educador em saúde. Rev Para Med. 2013;27(2):95-9.

5. Perrenoud P. A prática Reflexiva no ofício do professor: profissionalização e razão pedagógica. Schilling C, tradutora. Porto Alegre (RS): Art Med; 2002. 232 p.

6. Villas Boas BMF. Portfólio, avaliação e o trabalho pedagógico. 8. ed. Campinas (SP): Papirus; 2012. 191 p.

7. Vieira VMO, Sousa CP. Contribuição do portfólio para avaliação do aluno universitário. Est Aval Educ. 2009;20(43):235-55. http://dx.doi.org/10.18222/eae204320092047.

8. Perrenoud P. 10 Novas competências para ensinar. Ramos PC, tradutor. Porto Alegre (RS): Artmed; 2000.192 p.

9. Silva CJV, Caldato MCF, organizadores. Manual do Módulo de Interação em Saúde na Comunidade. Belém (PA): CESUPA; 2012. 93 p.

10. Fontanella BJB, Ricas J, Turato ER. Amostragem por saturação em pesquisa qualitativa em saúde: contribuições teóricas. Cad Saude Publica. 2008;24(1):17-27. PMid:18209831. http://dx.doi.org/10.1590/S0102-311X2008000100003.

11. Turato ER. Tratado da metodologia da pesquisa clínico-qualitativa. 5. ed. Petrópolis (RJ): Vozes; 2011. 685 p.

12. Bardin L. Análise de conteúdo. Reto LA, Pinheiro A, tradutores. Lisboa: Edições 70; 2006. 280 p.

13. Oliveira MM. Como fazer pesquisa qualitativa. 3. ed. rev. e ampl. Petrópolis (RJ): Vozes; 2010. 232 p.

14. Villas Boas BMF. O portfólio no curso de Pedagogia: ampliando o diálogo entre professor e aluno. Educ Soc. 2005;26(90):291306. http://dx.doi.org/10.1590/S0101-73302005000100013.

15. Moreto G. Uma nova metodologia docente em Bioética: experiência da aplicação do Portfólio com estudantes de Medicina. O Mundo da Saúde. 2010;34(3):341-6.

16. Troncon LEA. Avaliação do estudante de Medicina. Medicina. 1996 Out-Nov;29:429-39.

17. Hypolito D. O uso do portfólio, a reflexão e a avaliação. Integração. 1999;5(19):291-2.

18. Schön DA. Educando o profissional reflexivo: um novo design para o ensino e a aprendizagem. Costa RC, tradutor. Porto Alegre (RS): Artmed; 2008. 256 p.

19. Forte FDS, Vieira LB, Pessoa TRRF, Freitas CHSM, Ferreira MLSM. Portfólio: desafio de portar mais que folhas: a visão do docente de Odontologia. Rev Bras Educ Med. 2012;36(1, Supl 2):25-32. http://dx.doi.org/10.1590/S0100-55022012000300005.

20. Cunha MI. Conta-me agora! As narrativas como alternativas pedagógicas na pesquisa e no ensino. Rev Fac Educ. 1997;23(1-2). http://dx.doi.org/10.1590/S0102-25551997000100010.

21. Hoffman JL. Avaliação mediadora: uma prática em construção da pré-escola à Universidade. 32. ed. Porto Alegre: Mediação; 2012. $176 \mathrm{p}$.

\section{Contribuição dos autores}

Clóvis José Vieira da Silva participou de todas as etapas da pesquisa e da confecção do manuscrito. Aline Oliveira Ferraz contribuiu com a coleta de dados através das entrevistas, análise dos dados e confecção do manuscrito. Nara Macedo Botelho participou na concepção inicial, acompanhamento, orientação do estudo e elaboração do manuscrito. 